\title{
La socialización infantil bilingüe en San Isidro Buensuceso, Tlaxcala, México
}

\author{
Refugio NaVA NaVA \\ Facultad de Filosofía y Letras, Universidad Autónoma de Tlaxcala \\ refugionava@hotmail.com
}

Recibido: 6/11/2014

Aceptado:13/7/2016

\section{RESUMEN}

En este artículo se analiza el proceso de socialización infantil practicado en San Isidro Buensuceso, Tlaxcala, México. En esta comunidad, a diferencia de los pueblos vecinos, el $77 \%$ de su población total es bilingüe náhuatl-español y sólo el $23 \%$ se declara monolingüe en la lengua castellana. Para conocer las prácticas de socialización infantil bilingüe y sus efectos en la vitalidad y desplazamiento del náhuatl se realizó una investigación etnográfica en la comunidad por espacio de 12 meses, teniendo como colaboradores focales a tres familias. La investigación revela que no existe un único tipo de socialización infantil, sino tres tendencias que van de más náhuatl a más español. Los resultados muestran dos fenómenos de gran relevancia, por un lado, el alto nivel de bilingüismo practicado en la comunidad, apoyado por un conjunto de ideologías lingüísticas que no condenan el uso de la lengua indígena, permite que muchos niños aprendan el náhuatl fuera de su familia nuclear, con primos, amigos o vecinos. Por otro lado, el hecho de que la mayoría de las personas hablen las dos lenguas no permite observar con claridad que muchos niños, quienes son calificados por sus padres como bilingües, manejan un conjunto de géneros muy limitado en lengua indígena. Este hecho dificulta la comprensión de que el proceso de desplazamiento sigue su curso y que éste debe ser analizado desde una perspectiva más conversacional pues en esta comunidad el desplazamiento lingüístico no se da como substitución de sistemas completos, sino mediante el abandono gradual de determinados géneros discursivos.

Palabras clave: Socialización, náhuatl, bilingüismo, desplazamiento lingüístico, géneros discursivos.

\section{Bilingual Socialization in San Isidro Buensuceso, Tlaxcala, Mexico}

\begin{abstract}
In this article, we analyse the different processes of language socialization that are carried out in San Isidro Buensuceso, Tlaxcala, Mexico. In this community, $77 \%$ of the population is bilingual. They speak Nahuatl and Spanish, the remaining $23 \%$ are Spanish monolinguals. San Isidro Buensuceso is a particular case of language maintenance in the Malintzin region which is characterised by a rapid language shift. In most of the communities surrounding the Malintzin volcano, Nahuatl is mainly spoken by adults and late adults. Young people and children are fluent Spanish speakers with some command of Nahuatl as a receptive competence. For this research, an ethnographic work was carried out in the community with special attention to three families. The study shows that there is not a unique model of language socialization but three approaches on a continuum that goes from more Nahuatl on one extreme to more Spanish on the other. Two conclusions can be derived from the research. On the one hand, due to the high number of bilinguals in each family, some children do not learn Nahuatl from their parents but from some other members of the family or friends; on the other hand, child bilingualism disguises the real level of Nahuatl spoken by younger generations. The research shows that some children, although considered bilingual by their parents, command very few language genres in the indigenous language. This way, language shift continue growing without much noticing. This research contributes to the languages shift theory by signalling that languages do not disappear or are shifted at once but through the erosion and substitution of language genres.
\end{abstract}

Key words: Socialization, Nahuatl, bilingualism, linguistic displacement, discourse genres.

Sumario: 1. Introducción. 2. Etnografía de San Isidro Buensuceso. 3. La socialización infantil: fundamentos teóricos. 4. La socialización del bilingüismo en San Isidro Buensuceso. 5. Conclusiones. 6. Referencias bibliográficas. 


\section{Introducción}

El objetivo central de este trabajo es describir el proceso de socialización bilingüe y analizar la importancia que éste ha tenido para lograr una alta retención de la lengua indígena en San Isidro Buensuceso, Tlaxcala, (SIB). El trabajo muestra el papel central que la socialización infantil, junto a otros factores, tiene para la reproducción de la lengua y la cultura nahua, pero al mismo tiempo, advierte que bajo la máscara del bilingüismo, se oculta un proceso de pérdida paulatina de géneros lingüísticos ligados a la cultura nahua.

El proceso de socialización infantil bilingüe es uno de los múltiples factores que posibilitan la retención del náhuatl en SIB. Aunque esta comunidad no escapa al incesante proceso de desplazamiento etnolingüístico que ha caracterizado a la región de la Malintzin en los últimos 60 años, sí representa hoy el bastión más importante en términos del uso de la lengua indígena, ya que a diferencia de la mayoría de las comunidades aledañas, en las que el náhuatl es utilizado sólo por los adultos y ancianos, en SIB encontramos hablantes de esta lengua en todas las generaciones. La retención etnolingüística en SIB resulta más destacada si señalamos que no se trata de un espacio donde prima el monolingüismo en lengua indígena, sino el bilingüismo náhuatl español entre la mayoría de sus habitantes. Por la impresionante riqueza en las prácticas culturales, así como por el incesante proceso de sincretismo cultural que se vive todos los días, esta comunidad resulta un espacio ideal para investigar cómo los grupos indígenas articulan prácticas culturales propias con las occidentales o las de otros grupos indígenas, en temas como la salud, la organización familiar, los procesos de enculturación, la distribución del trabajo, la relación de la naturaleza con el hombre, el mantenimiento de la fertilidad de la tierra, la herencia y el arte, entre otros; para ello, es imprescindible un abordaje interdisciplinar que estudie la cultura como un entramado orgánico.

La investigación se realizó utilizando el método etnográfico en tres espacios diferentes, la casa, la escuela y los lugares públicos. Cabe señalar que no todas las familias socializan a sus hijos en forma bilingüe, por lo que se eligieron a tres familias que sí lo hacen y con quienes ya se había trabajado previamente para documentar el habla adulta. La relación establecida durante el trabajo previo permitió un elemento fundamental: que la investigación se realizara en lengua náhuatl. Este hecho, que pudiera parecer poco relevante se vuelve central cuando el tema de investigación es precisamente el mantenimiento de la lengua indígena ligado a contextos que «indexicalizan» su uso.

El hecho de que la mayor parte de la población sea bilingüe ha organizado los contextos y los patrones de interacción de cada una de las dos lenguas bajo criterios locales. La selección de lengua para un determinado evento comunicativo está sujeta a factores como la identidad de los participantes, su pertenencia o no a la misma red social, el tipo de evento comunicativo y el lugar donde ocurre la interacción, entre otros. Cada persona participa en distintas redes sociales y comunidades de práctica en las que una de las dos lenguas se usa en forma primaria. Este habitus (Bourdieu 1979, 1980, 1990) permite que un hablante utilice el náhuatl con algunas personas y el español con otras, pese a que todos los involucrados sean hablantes de ambas lenguas. 
Ante esta circunstancia es importante destacar la efectividad de los patrones de socialización lingüística tanto vertical (de padres a hijos) como horizontal (entre pares) para que los niños adquieran una competencia comunicativa en lengua indígena. El mantenimiento del náhuatl se debe entre otros factores a que los niños, a distintas edades, también son agentes que deciden qué lenguas hablar (Nava en prensa). Muchos de ellos llegan a adquirir cierto nivel de náhuatl con sus hermanos, primos y compañeros de juego pese a que sus padres prefieran orientarlos más hacia el español, al hablarles sólo o principalmente en esa lengua. De igual manera, el prestigio de los agentes culturales que hablan y promueven el náhuatl en la comunidad tales como los profesores y los investigadores resulta importante ya que rompe el paradigma de asociar la lengua indígena con hablantes pobres, campesinos y particularmente sin una incursión destacada en la cultura hispanoparlante. Ellos contribuyen a construir un concepto del uso del náhuatl como una elección y un derecho y no como signo de atraso o incapacidad para aprender otras lenguas.

\section{Etnografía de San Isidro Buensuceso}

SIB está ubicado al suroeste del estado de Tlaxcala, México, a 2600 m s.n.m. en las laderas del volcán la Malintzin, pertenece políticamente al estado de Tlaxcala aunque social y culturalmente mantiene una relación muy estrecha con los pobladores de San Miguel Canoa, Puebla. Su relación parece ser muy antigua ya que se remonta a la propia fundación de SIB. Rendón (1993) señala que San Isidro no fue un asentamiento prehispánico sino que, al parecer, se inició como una hacienda en el siglo XVII y su transformación a pueblo tuvo lugar en el año 1900. Durante la revolución mexicana, la región de la Malintzin fue severamente afectada, gran parte de la población abandonó temporalmente sus comunidades para ocultarse en el volcán. En la segunda mitad del siglo XX la región de la Malintzin fue azotada por una peste que diezmó seriamente la población de la región. Según Aztatzin (1991), gente de varios pueblos huyó hacia lo más alto de la montaña donde el contagio no había llegado y se instaló allí permanentemente. Esta «zona relativamente libre del reclutamiento y de las epidemias que arrasaban sus comunidades» (Francis 1997: 153) era la región de San Isidro Buensuceso. Con este nivel de aislamiento relativo y con la poca relación con la cabecera municipal, SIB vivió durante muchos años sin la mirada vigilante de los extraños, ya que la gente de la comunidad salía a trabajar a las ciudades, pero poca gente entraba a ella.

En 1959 Hugo Nutini realizó el levantamiento etnográfico de 77 comunidades nahuas de la región de Tlaxcala y Puebla. Una de esas comunidades fue SIB. Aunque el resultado de sus investigaciones no se publicó hasta 1974, la fecha del levantamiento de los datos resulta de gran importancia para formarnos una idea de la manera en la que los adultos y ancianos de la comunidad vivían en esa época:

«San Isidro está conectado por veredas con San Miguel Canoa y con San Pablo del Monte unos 10 kilómetros más abajo. Dos camiones diarios hacen el servicio a San Miguel Canoa [desde Puebla] pero los camiones no llegan a San Isidro porque la barranca que separa estos pueblos es abrupta y profunda» (Nutini e Isaac 1974: 87). 
«Algunas casas se hacen de mampostería, pero la mayoría son de adobe con techos de tejamanil» (ibid: 88). «Se carece por completo de industria local [...]. Los hombres realizan los trabajos agrícolas con considerable ayuda de las mujeres. Éstas sacan agua del pozo, casi siempre perforado junto a la misma casa [...]. Hay cierta reciprocidad dando trabajo a cambio del uso de equipo o de animales de tiro pero generalmente los servicios agrícolas se pagan en efectivo [...]. Muy pocos buscan trabajo fuera de la localidad» (ibíd.: 89). «El pueblo es bastante indígena tanto racial como culturalmente y a nadie en San Isidro se le llama «gente de razón» [...]. «En San Isidro predomina la vivienda multifamiliar» (ibíd: 90). «Sólo hay una iglesia en el pueblo y ninguna capilla» (ibid: 91).

Esta imagen contrasta con la encontrada por Francis (1997) en algunos aspectos, pero mantiene una lógica propia en la organización familiar y el uso del náhuatl:

«Sólo en un sentido relativo, más bien desde un punto de vista histórico, se podría decir que San Isidro es la más aislada de las comunidades de la Malintzin. Mientras que el camino de asfalto que comunica al pueblo con la cabecera municipal lleva menos de 10 años sirviendo como principal vía de acceso a los centros urbanos, el servicio de transporte diario a Puebla ha estado al alcance de la población, por lo menos, desde los años 50 de Canoa (quince minutos caminando de la iglesia hasta la plaza) (Francis 1997: 144).

Hoy, llegar a esta comunidad es muy fácil y rápido desde cualquier punto de la ciudad de Puebla o desde la capital del estado de Tlaxcala. La carretera de cuatro carriles Santa Ana-Puebla conecta con otra carretera, igualmente pavimentada que, tras recorrer unos $12 \mathrm{~km}$, nos permite llegar al centro de San Isidro Buensuceso. Viajar de SIB a la capital del estado de Puebla, centro urbano por excelencia de la gente de esta comunidad, toma aproximadamente media hora.

En el tipo de vivienda, hoy existe una gran diversidad. La mayoría de las casas son de mampostería y cada día aumentan considerablemente las casas de dos plantas y con arquitectura propia de las zonas urbanas. Pese a esto, las casas combinan «la modernidad del cemento» con las necesidades locales de espacio: el patio, la troje, la cisterna y el temascal son indispensables en la mayoría de los hogares.

En el terreno de las prácticas culturales, la alta interacción de la gente de SIB en las ciudades con otros grupos culturales, les ha permitido conocer e incorporar otras prácticas a su conducta diaria. Las innovaciones de los más jóvenes encuentran acomodo entre las manifestaciones locales históricamente arraigadas, incluso en aquellas altamente ritualizadas. Aunque existen casos extremos en los que las nuevas manifestaciones han substituido a las locales, como por ejemplo la vestimenta nativa que algunos adultos señalan «todavía haber conocido», en la actualidad se puede observar la presencia de elementos provenientes de diversas matrices culturales que han encontrado acomodo cumpliendo funciones distintas, provocando con ello un enriquecimiento de la práctica cultural en vez de una substitución total.

El pueblo ha crecido enormemente. SIB tiene una población total de 8.769 habitantes, sin embargo, para elaborar los datos estadísticos en la variable lengua indígena, el Instituto Nacional de Estadística, Geografía e Informática (2010), considera solamente a las personas de 3 años y más. Siguiendo este criterio, de los 8.141 habitantes 
mayores de 3 años, 6.300 que representan el 77,3\% habla la lengua indígena, el otro $22,7 \%$ habla sólo español.

De las 6.300 personas que sí hablan náhuatl, 6.110 también hablan español y el resto, 190, son monolingües en lengua indígena. Los datos expuestos describen cuantitativamente a SIB como la comunidad tlaxcalteca con la más alta retención etnolingǘstica, pero al mismo tiempo evidencian un proceso de desplazamiento constante pues casi un cuarto de su población se asume como monolingüe en español. Este hecho ha sido apuntado desde la última década del siglo pasado por investigadores como Francis quien señala:

«El proceso de la sustitución del náhuatl tal vez no atraviese el umbral crítico de la no recuperación como en las comunidades del valle. Pero como hacen patentes las correlaciones socioeconómicas, no hay razón para dudar que los Buensuceso y Canoas de 1990 serán los Tetalanohcan y Cuauhtenco del mañana» (Francis 1997: 148).

Antes de que esto ocurra, es necesario llevar a cabo una investigación profunda sobre el proceso de desplazamiento no sólo cuantitativamente, sino, particularmente, en términos cualitativos, pues el hecho de que un mayor número de personas se declare bilingüe y que la etnografía de la comunidad corrobore este dato, significa que en determinados géneros lingüísticos y/o contextos de interacción, el náhuatl está siendo substituido, dentro de la propia comunidad, por el español. El dato cuantitativo, en términos del número de los que hablan la lengua indígena, no muestra con fidelidad el proceso de desplazamiento pues algunos hablantes utilizan sólo unos cuantos géneros discursivos o hablan la lengua indígena sólo con determinadas personas o, aunque se catalogan como hablantes, su dominio y espacios de uso son muy reducidos.

Cada hogar se convirtió en un contexto cuyos integrantes manejan un nivel de competencia lingüística muy diverso. Debido a esto, al principio, el bilingüismo resultó necesario para establecer comunicación entre los distintos actores. A pesar de que algunos miembros de cada familia ya hablaban español, otros eran monolingües o casi monolingües en náhuatl. Por otro lado, el hecho de que una persona, en la edad adulta, aprendiera español no significaba que de manera inmediata dejaría de hablar la lengua indígena ya que eso implicaría rechazar su adscripción a sus distintas redes sociales en la comunidad.

En la etapa en que más adultos empezaban aprender español, finales de los años 60 del siglo pasado, apareció en la comunidad un sacerdote que, de manera explícita promovía el bilingüismo náhuatl-español en vez de una transición directa hacia el monolingüismo en la lengua nacional. Don Rafael Cahuantzin, sacerdote oriundo de San Bartolomé Cuahuixmatlac, una comunidad nahuahablante de Tlaxcala, predicó esta ideología lingüística con el ejemplo y, aprovechando su conocimiento de la religión en lengua indígena, pues había sido profesor de náhuatl mientras realizaba sus estudios sacerdotales, continuó con mayor vigor una tradición iniciada años atrás en la comunidad: usar el náhuatl en ejercicio del ministerio católico. A esto, agregó la práctica de hablar de la importancia de mantener la lengua indígena entre padres e hijos independientemente de aprender otras (Cahuantzin, comunicación personal 2006). Este cuerpo ideológico a favor del bilingüismo llegó a ser reforzado años más tarde por diversas instituciones educativas con orientación bilingüe. En 1981 se estableció en la comunidad el primer preescolar bilingüe llamado Kalpilton (casa 
del niño) y en 1988 la escuela primaria, que hasta entonces había funcionado bajo el modelo monolingüe en español, cambió al subsistema de educación indígena.

El Consejo Nacional para el Fomento Educativo opera en esta comunidad desde 1999 y a la fecha mantiene espacios educativos para preescolar, primaria y secundaria con diversos grados de bilingüismo.

Aunque el trabajo en términos del uso de la lengua indígena en el aula varía de institución a institución, lo que todos los sistemas tienen en común es la campaña permanente de promoción del uso del náhuatl en el hogar y en ciertos espacios escolares. Las instituciones han trabajado para lograr la validación ideológica de una práctica que en muchos otros lugares de la región fue sancionada: el uso de la lengua indígena hacia la población infantil, pues en los primeros años de la segunda mitad del siglo $\mathrm{XX}$, en gran parte de la región nahuahablante de Tlaxcala se puede documentar una campaña negativa hacia el uso de la lengua indígena entre y hacia los niños (Robichaux 2007). Tal situación llegó a generar que incluso los abuelitos, tremendamente dominantes en lengua indígena, hicieran esfuerzos extraordinarios para hablar con sus nietos sólo en español.

Esta campaña en pro del náhuatl llevada a cabo por las instituciones escolares en tiempos recientes tuvo un efecto positivo al impactar en el modelo de familia extensa. El hecho de que en un mismo solar, y a veces en una misma casa, lleguen a vivir hasta 4 generaciones juntas brinda la oportunidad a los niños de estar rodeados permanentemente de interacciones tanto en náhuatl como en español. Insistir en la vigencia de una ideología que promueve el bilingüismo resulta importante ya que si bien el modelo de familia extensa favorece que el niño esté en contacto con la lengua indígena, en las comunidades vecinas donde prima también este modelo pero una ideología opuesta, los resultados fueron diferentes, los niños y jóvenes prácticamente no hablan la lengua nativa.

Este planteamiento nos muestra que la continuidad en el uso del náhuatl no sólo tiene que ver con la existencia de suficiente input en esta lengua, sino también con la disposición de los abuelos, padres e hijos de seguirla usando como el principal vehículo de comunicación. Esta decisión está atravesada por varias aristas y, entre ellas, una de las más importantes es el capital simbólico que esta lengua representa.

\section{La socialización infantil: fundamentos teóricos}

Las culturas de los grupos indígenas mexicanos tienen su propia lógica y, sin pretender encerrase sólo en su visión propia, articulan capitales culturales con otros grupos manteniendo y construyendo etnogénesis que le dan identidad y sentido a sus vidas. Sobre el imaginario de los grupos indígenas en México destacan trabajos importantes de autores como Gossen (1972, 1979), Galinier (1990), Good (2001), Saucedo (2003) y López Austin (1989), entre muchos otros que han abierto caminos aún pendientes por ser explorados sobre aspectos importantes de la cosmovisiones nativas.

En este marco, la socialización del lenguaje juega un papel central pues es el proceso a través del cual una persona llega a ser un miembro competente de su sociedad (Schieffelin y Ochs 1986). Para abordar la socialización desde esta óptica es preciso 
incorporar una perspectiva sociocultural que dé cuenta de la manera en que los niños desarrollan conceptos de un universo sociocultural estructurado a través de su participación en actividades verbales. Schieffelin y Ochs (1986) señalan que es a través del lenguaje, no sólo como canal sino como proceso social, que el niño se encuentra con información tanto lingüística como cultural respecto de los patrones de su grupo. De este modo, un infante aprende roles, turnos de habla, rasgos estilísticos, géneros discursivos y patrones de interacción no de manera pasiva sino de un modo activo, como un participante. De León (2005: 124) postula, a partir de sus investigaciones con los zinacantecos de Chiapas, una «microgénesis del participante: del protohablante y protointerlocutor, al hablante incorporado, al compañero vocal conversacional». Como podremos observar, la clave de este enfoque para la socialización infantil es la concepción del niño como participante directo en cada interacción. La socialización no es un mero ejercicio de transmisión de contenidos de unos hacia otros, es un trabajo de construcción de significados mediante la participación en actividades cotidianas de los entes socializados. En esta concepción:

«El lenguaje no transmite valores culturales sino más bien, a través de la participación en prácticas en curso del lenguaje, el niño construye información sociocultural. A través de interacciones con una variedad de significantes, otros niños no solamente aprenden a comunicar sino también a través de tales comunicaciones adquieren maneras culturalmente relevantes de ser, sentir y hacer» (Nancy Budwig, citado en Terceros 2002: 31).

La vivencia es central no sólo para internalizar un habitus, sino también para desarrollar un cuerpo de creencias e ideologías que sustenta tales prácticas:

«Los niños y otros novatos en la sociedad adquieren conocimiento tácito de los principios del orden social y los sistemas de creencias (etnoteorías) a través de la exposición a y a la participación en interacciones mediadas por la lengua» (Schieffelin y Ochs 1986: 2).

Es importante hacer notar que no todas las culturas del mundo siguen un solo patrón para socializar a sus niños. Diversos estudios (Crago 1992; De León 2005; Schieffelin 1990) han mostrado que existe una especificidad cultural que determina distintas formas de concebir a la niñez y las formas en que un niño entra en contacto con la lengua. Por ejemplo, Schieffelin (1990) describe que la cultura kaluli no le otorga a los recién nacidos el estatus de interlocutores y los adultos prácticamente no se dirigen a ellos de manera verbal. Por lo tanto, durante los primeros 18 meses de vida aproximadamente, los niños son asistidos por sus padres (especialmente la madre) pero sin crear interacciones diádicas.

Los samoanos (Ochs 1988) tienen un patrón similar y así, desde su nacimiento hasta la edad de 5 o 6 meses, a los niños no se les reconoce como interlocutores válidos. Se habla de los niños y no a los niños. En el caso en el que se hable a los niños, se hace con canciones o vocalizaciones rítmicas en tono suave, pero no se entablan conversaciones con ellos. Los balbuceos son interpretados en términos del estado psicológico que los origina: alegría, tristeza, malestar físico, pero no en términos de respuesta a una interpelación. Cuando el bebé empieza a gatear, súbitamente sus familiares comienzan a dirigirse verbalmente a ellos. El estilo comunicativo usado para 
dirigirse a los niños de esta cultura es directo, a base de imperativos sin modificación del lenguaje.

Ahora bien, la socialización infantil no puede estudiarse fuera del entramado cultural completo. La socialización del lenguaje forma parte del proceso de enculturación $\mathrm{y}$, por lo tanto, se nutre de elementos mayores como el concepto de persona, niñez, comunicación cotidiana y ritual, sobre todo en esta lengua que cuenta con un amplio sistema de honoríficos; ideologías lingüísticas, redes sociales, géneros discursivos y un largo etcétera. Por las características y propósitos de un artículo como éste, no podemos dar cuenta de todos estos recursos, sin embargo, sí consideramos preciso abordar a continuación tres conceptos estrechamente ligados al tema de estudio: las ideologías lingüísticas, los géneros discursivos y las redes sociales.

Silverstein (1979) concibe a las ideologías lingüísticas como un cuerpo de creencias acerca de la lengua, articulada por los usuarios como una racionalización o justificación de la forma en la que se percibe la estructura y el uso lingüístico. Esta opinión focaliza el carácter verbalizable de la ideología y que efectivamente usamos para «justificar», por ejemplo, por qué el español es «mejor» que el náhuatl o por qué el náhuatl es «tan valioso» como el español». Sin embargo, para conocer las ideologías lingüísticas de una persona no basta con preguntar aspectos sobre la lengua, Woolard (1998: 6) señala que:

«En la teoría más reciente, la ideología no [se concibe] como necesariamente consciente, deliberada, o como pensamiento sistemáticamente organizado, es actuado, práctico, prereflexivo o estructural».

Esto significa que el etnógrafo debe inferir en primer momento los significados sociales implícitos en los discursos, posteriormente debe escuchar lo que se dice sobre los usos del lenguaje, particularmente cuando comparan sus variedades con las de los pueblos vecinos, o cuando una persona llega a la comunidad hablando otra variedad de su lengua. La comparación de variedades o la explicación sobre la razón por la cual una persona es bilingüe permite descubrir algunos de los principios que subyacen a sus ideologías lingüísticas; en este sentido coincidimos con el planteamiento de Van Dijk (1988: 245) quien señala que «en confrontaciones interactivas con miembros de otros grupos, las personas están capacitadas para explicar, defender o legitimar discursivamente sus ideologías».

Las ideologías lingüísticas permiten comprender ciertos aspectos del mantenimiento o desplazamiento de una lengua indígena. Sin embargo, en espacios bilingües las lenguas se distribuyen generalmente en un mismo contexto y se requiere una unidad de análisis mayor a la noción de contextos mismo. Ante ello, propongo utilizar el concepto de género discursivo, mismo que se define como:

«Una constelación de potencialidades de convenciones discursivas, sustentada por los conocimientos previos de los hablantes /escritores y oyentes/ lectores (almacenados en la memoria de cada sujeto), a partir de constricciones y parámetros contextuales, sociales y cognitivos. Dicho conocimiento - construido sociocognitivamente- se articula de modo operativo a través de representaciones mentales altamente dinámicas. Así, el género -como potencialidad de recursos- se instancia en conjuntos de selecciones convencionalizadas, las que presentan determinadas regularidades sincrónicamente identificables, pero que también son factibles de ser observadas a modo de variaciones 
diacrónicas, pues no son entidades de modo estático sino altamente dinámicas» (Parodi 2009: 34).

El hecho de que los géneros tengan «conjuntos de selecciones convencionalizadas» permite que el individuo no se enfrente a la disyuntiva sobre cuál de sus dos lenguas deberá utilizar en cada interacción, existe una regularidad establecida y aunque, efectivamente, también hay ocasiones en que el contexto se modifica e ingresa un nuevo elemento, hay un sólido patrón sobre el cual se toman las decisiones que solucionan esa demanda. Bakhtin advierte sobre el tema de los géneros como estructuras convencionalizadas de la siguiente manera:

«[Los géneros discursivos] tienen un significado normativo para el hablante y no son creados por él, sino que le son dados. Si los géneros discursivos no existieran y nosotros no los hubiésemos dominado, si nosotros tuviésemos que crearlos durante el proceso comunicativo y construir cada enunciado a voluntad por primera vez, la comunicación sería casi imposible» (Bakhtin 1986: 78).

Así, cada lengua está más ligada a un determinado género y el hablante actualiza ese registro en cada ocasión. Sin embargo hace falta llevar a cabo una investigación más profunda para realizar un inventario de géneros discursivos en comunidades bilingües, pues aunque superficialmente pareciera que se está haciendo lo mismo en una lengua y en la otra, en el imaginario, en cada género discursivo se lleva a cabo una acción y lo que implica esta acción, es distinto en cada lengua; por otro lado, Gossen (1972: 145) advierte que «la clasificación de los géneros europeos son frecuentemente inadecuados para la descripción de tradiciones orales no occidentales». Esta opinión es de vital importancia ya que es precisamente la especificidad de los géneros en cada lengua lo que hace que la gente lleve a cabo determinados eventos en una lengua determinada. Observar el uso de la lengua desde la perspectiva de los géneros discursivos (Bakhtin 1981, 1986; Gossen 1972) resulta de gran utilidad para explicar conceptos como el de hablante de una lengua determinada que en comunidades multilingües tienen un significado particular. Usando la teoría de los géneros discursivos se puede abordar tanto el desplazamiento de la lengua indígena como el aprendizaje de una segunda lengua de una manera más efectiva. Si creemos que el desplazamiento ocurre a nivel de géneros discursivos, entonces podremos observar con mayor claridad cómo determinados géneros discursivos se van moviendo de una lengua hacia otra, pero al mismo tiempo cómo algunos de ellos permanecen mayor tiempo en la lengua en la que originalmente fueron acuñados.

La relación entre los géneros discursivos y las ideologías lingüísticas se anclan en grupos humanos que Milroy (1980) y Milroy y Milroy (1992) denominan redes sociales. Estas redes son distintas a las clases sociales ya que las primeras se basan en la solidaridad y las segundas en la jerarquía. Las redes sociales permiten ubicar a un individuo en diferentes nodos construidos a partir de categorías que tienen cierta historicidad (habitus) y que hacen posible la reproducción de ciertas conductas. Un individuo no se presenta de igual manera en cada una de sus redes, sino que construye y despliega identidades diferentes. La flexibilidad de las redes sociales permite ver al individuo en una faceta multifuncional y no preso por una única categoría cerrada. La propia red social, sin ser necesariamente homogénea, encuentra formas de digerir 
sus diferencias y al mismo tiempo consolidarse como unidades diferentes a otras redes. Milroy (1980) señala que las redes sociales cerradas funcionan como una fuerza conservadora, ésta exhibe alta densidad y multiplicidad, es decir, todos en la red conocen a todos (densidad) y además se conocen en otras de sus facetas o roles (multiplicidad). Milroy y Milroy (1992) señalan que estas redes sociales cerradas resisten presiones de cambio originadas desde el exterior y tienen la capacidad de mantener e incluso, reforzar las convenciones y normas locales, incluyendo formas lingüísticas.

Las redes sociales y las ideologías lingüísticas influyen de manera importante en la socialización del lenguaje. El papel de la socialización es central ya que mediante este proceso se reproduce y modifica la estructura social. En el tema de la retención o el desplazamiento etnolingüístico, el estudio de la socialización infantil nos permite ver cómo se desarrolla la competencia comunicativa del niño (Hymes 1974) de acuerdo con los parámetros de su comunidad de habla.

Usar una lengua indígena en una comunidad como SIB no es un asunto que tenga que ver sólo con el nivel de competencia del hablante, sino con la identidad de dicho hablante validada por su grupo social. Es la propia comunidad quien ratifica o rechaza el rol de hablante de lengua indígena a un niño al momento de interactuar con él. Esta ratificación o negación no ocurre necesariamente de manera directa, es decir, no se precisa decirle al niño si debe o no hablar la lengua indígena, se da, principalmente, en la presencia o ausencia del náhuatl en el momento en que los padres interactúan con sus hijos. Los niños vivencian la distribución de lenguas para cada miembro de la familia y construyen sus roles y la lengua que, en cada caso, deben usar en función de los criterios de su o sus comunidades de habla.

Con este enfoque en el abordaje de la socialización infantil podremos mostrar que la retención de la lengua indígena en SIB está sustentada en el mayor o menor uso que los padres, abuelos y pares realizan de la lengua indígena al momento de interactuar con los niños. También, se propone que tal retención no es sinónimo de vitalidad lingüística pues aunque tres cuartas partes de la población sean bilingües, en muchos casos, particularmente entre los niños, el manejo que tienen de los géneros lingüísticos es limitado.

\section{La socialización del bilingüismo en SIB}

La socialización de los niños de San Isidro Buensuceso tiene lugar en un ambiente bilingüe a distintos niveles. El modelo de estructura familiar que consiste en agrupar a una familia extensa en un espacio físico pequeño, permite que los niños sean socializados en grupos conformados por abuelos, padres, hermanos, primos, sobrinos, tíos, etc. Una primera observación importante es que los padres que viven bajo este modelo familiar no son los únicos que pueden decidir la lengua que hablarán sus hijos. Aún cuando ha habido casos en los que los padres de familia han decidido que sus hijos hablen una sola lengua, el español, la socialización colectiva así como la lengua de la comunidad juegan un papel muy poderoso que permite, en ciertos casos, que los niños adquieran la lengua indígena fuera del núcleo familiar. Esta observa- 
ción ha sido también registrada por la propia gente de la comunidad como da cuenta la siguiente cita:

«Cequi quinpāctia de mexicano pero cequi ōcachi zān español. Huelīca tlazāloah mexicano, pos huelīca, porque... neh niquittā cē pipiltōntzī, nōn quinōtzah puro español pero huelīca tlahtoa mexicano, huelīca. Mahuiltitīhueh, ye monentlapuiah de mexicano, quihtoah: ¿cānin ca in trompo? Huelica. Tlā quihtoah: «neca». Ihcōn ye motlapuiah pos ihcon ye quizālohtīhueh» (Mujer, 43 años)

«A algunos [padres] les gusta el mexicano ${ }^{1}$ pero a otros sólo el español. [Los niños], de cualquier modo, aprenden el mexicano, de todos modos, porque... yo veo a un niño, a él le hablan sólo en español pero de todos modos habla mexicano. Los niños van a jugar, platican entre ellos muchas cosas en mexicano, dicen: ¿dónde está el trompo? (en mexicano), de todos modos. Si dicen «allí» [está el trompo]. Así platican, pues así ya van aprendiendo [el náhuatl]» (Mujer, 43 años).

Un caso concreto a este respecto es lo que ocurre en la casa de la señora Lupita. Lupita es casada y tiene 4 hijas. Vive en el mismo solar que su madre y sus dos hermanas casadas. Los niños de las tres familias nucleares conviven todos los días juntos. Juegan en el mismo espacio y van a la misma escuela. Lupita trabajó en San Pablo del Monte y en la ciudad de México antes de casarse. Ella piensa que es necesario saber español muy bien para conseguir un trabajo en la ciudad. Por eso, ella habla a sus hijas mayoritariamente en español. Pese a esto, sus hijas hablan náhuatl. La razón de ello es que los otros niños de la familia extensa son socializados en lengua indígena en el patio común. La propia madre señala: «se van a jugar con sus primos, pues, ¿qué van a hablar si no mexicano?, se juntan todos y ya todo es en mexicano, pues ni modos que no jueguen». Este ejemplo muestra el papel activo de los niños en tanto agentes de algunos aspectos de su propia socialización y su membresía a distintos grupos. La formación del niño en términos de un ser social no está de ninguna manera exclusivamente sujeto a la voluntad ni poder de los padres, el niño, fuera de la misma familia extensa, en la escuela, por ejemplo, construye nuevas ideologías y adquiere membresías a grupos distintos que pueden tanto suprimir como activar su uso del náhuatl en determinados contextos.

\subsection{Tendencias de socialización en San Isidro Buensuceso}

Entre los elementos más importantes que han contribuido a que hoy la comunidad exprese una enorme heterogeneidad lingüística encontramos tres tendencias de socialización que consideran la retención del náhuatl desde perspectivas diferentes. Las tres tendencias de socialización a las que hacemos referencia son: 1) Socialización mayoritariamente en náhuatl, 2) Socialización diferenciada en los dos idiomas por agentes distintos y 3) Socialización mayoritariamente en español. Como se verá en la discusión que sigue, estas tendencias no han creado necesariamente tres grupos

1 En la región de Tlaxcala, el término náhuatl fue introducido por la escuela, los propios hablantes denominan mexicano a la lengua que hablan. 
de personas diferenciados lingüísticamente. Lo que ha ocurrido es que, a partir del funcionamiento de los distintos patrones de socialización, se ha hecho más visible que este proceso no sólo ocurre de manera vertical, de padres a hijos, sino también de manera horizontal, entre pares. A continuación describimos cada una de las tendencias y su impacto en el proceso de retención de la lengua indígena.

\subsubsection{Socialización mayoritariamente en lengua náhuatl}

A partir de la narración de los padres de familia respecto a la edad a la que aprendieron español, del señalamiento de los adultos respecto a que el náhuatl fue la lengua que aprendieron en primer lugar y de la convivencia con algunas familias que manejan este patrón hacia sus niños, podemos señalar que la socialización mayoritariamente en náhuatl empezó a disminuir de manera acelerada hace unas tres décadas. Aunque hoy día encontramos algunos casos de este tipo, lo cierto es que éstos son los menos y ocurren fundamentalmente entre familias cuyo trabajo está más relacionado con el cultivo de la tierra o el trabajo en la montaña. Como estas personas no participan en redes sociales donde las exigencias lingüísticas demanden un uso sistemático del español, su dominio de esta lengua sólo abarca algunos géneros discursivos básicos para interactuar durante la comercialización de sus productos. En estos hogares la lengua principal de la casa es el náhuatl y la socialización tiene lugar mayoritariamente en esta lengua.

Las personas que manejan una socialización temprana de este tipo conciben a su comunidad como fundamentalmente nahuahablante. La siguiente es la contribución de una mujer cuyo hogar es más dominante en lengua indígena:

«Nicān puro mexicano titlahtoah. Puro mexicano. Amācah quihtoa pos ¿ttlēca nontlahtoah mexicano? Nicān ihcōn. Ācah ihcōn cānah yōyah, cuāe huītz ihcōn ōchuel. Huān quīmi orita ōpanoc in zoātzīntli, in señora de nican, novecina, ¿ ¿tlen tconchīhua? Mach tleno. Ihcōn cē monōtza» (Mujer, 35 años).

«Aquí hablamos puro mexicano. Puro mexicano. Nadie dice: pues ¿por qué hablan mexicano? Aquí así [es], [si] alguien va a algún sitio, cuando regresa, [habla] otra vez así. Y como ahorita pasó la señora, la señora, mi vecina, [me dice:] ¿Qué hace?, [le contesto] nada. Así hablamos» (Mujer, 35 años).

Los niños de estos hogares aprenden como primera lengua el náhuatl y a medida que se van incorporando a mayores redes sociales van adquiriendo el español.

En algunas familias donde el náhuatl es la lengua dominante de sus padres y abuelos, son los niños quienes, en la escuela, desarrollan el mayor nivel de español y, por lo tanto, terminan funcionando como intérpretes entre sus padres y la sociedad hispanoparlante.

La etapa del monolingüismo en lengua indígena entre los niños puede durar muy poco tiempo a partir del momento en que inician su incursión en los ambientes más bilingües. Sus hermanos, dos o tres años mayores que ellos, se encargan de incorporarlos a redes sociales más amplias en las que el español también está presente. Llama la atención la rapidez con la cual estos niños empiezan a utilizar el español, 
eso supone que antes de convertirse en usuarios, han acumulado un capital como bilingües teniendo su español como competencia pasiva en tanto no contaban con un interlocutor para usarlo.

\subsubsection{Socialización bilingüe}

Dado que la mayoría de la gente en SIB es bilingüe, los niños están permanentemente expuestos al uso de la lengua indígena y al español. Si bien este hecho significa que los niños tienen el input necesario para adquirir el náhuatl, la evidencia empírica en la región señala que éste es sólo uno de los múltiples componentes necesarios para tal fin. En muchos de los hogares de las comunidades vecinas, los adultos también hablan la lengua indígena y sin embargo, los niños no la adquieren (Hill y Hill 1986) $\mathrm{y}$ aún si llegan a adquirirla, no la usan de manera sistemática en sus interacciones cotidianas.

Lo que hace posible que los niños de San Isidro hablen la lengua indígena es que, además del contexto nahuahablante en el que están inmersos, la propia sociedad los valida como hablantes de esta lengua. Es decir, para la mayoría de los padres de familia de esta comunidad la lengua indígena no representa ninguna amenaza para sus hijos, y por lo tanto aceptan que éstos interactúen en ella. Las ideologías lingüísticas profesadas por los habitantes de esta comunidad y las prácticas de socialización están orientadas a la reproducción del bilingüismo, no a la substitución de la lengua indígena por el español. Por otro lado existe una clara idea de que en la comunidad existen las condiciones necesarias para la reproducción de la lengua indígena. Se da por hecho que los niños tarde o temprano terminarán hablando náhuatl y que resulta una tarea muy difícil «arrancar» el náhuatl de esta comunidad. Así lo expresa don Pedro², un defensor del náhuatl en la comunidad:

«¿Cān ōctzēcuēhuazqueh? Āxān, mōztla, huīptla, todos los tiempos. Āmo polihuiz. Nīn idioma, siempre yez adelante huān āmo tlamiz in tradicion, tiene que llevar. ¿No así lo considera? Ca enraizado, puesto cē manera positivo, Tehhuān como original, nativos de nicāh, ticateh enraizados. Āco, āmo pilihuiz, ca enraizado quēme cē retoño, quēme cē planta. Titlahtozqueh den encinos. Ah, ompa yahui in talador, run run yeca, yōc...de momento quēme ōquitzauc nīcamac, cállate tantito pero el nuevo retoño... ¿cuándo polihiuz? Amo polihuiz» (Hombre, 60 años).

¿Cómo lo van a arrancar [el náhuatl]? Hoy, mañana, pasado mañana, en todos los tiempos. No se perderá. Este idioma siempre irá adelante y no terminará la tradición. Tiene que continuar. ¿No lo considera así? Está enraizado, puesto de una manera positiva. Nosotros como originales, nativos de aquí, estamos enraizados. No, no se perderá. Está enraizado, como un retoño, como una planta. Hablemos de los encinos. Ah, Allá va el talador (hace el ruido de la sierra) run run ya lo [tiró], ya...de momento como que le calló la boca, [le dijo al árbol:] cállate tantito...pero el nuevo retoño [brotará] ¿cuándo se va a perder? No se va a perder» (Hombre, 60 años).

2 Pseudónimo 
Bajo la premisa de la continuidad, la socialización bilingüe no sucede bajo un único patrón. En algunos casos, son los propios padres de familia quienes, a través de la interacción con sus hijos, participan en el desarrollo de su competencia comunicativa en lengua indígena. En otros casos, los niños aprenden el náhuatl al interactuar con otros miembros de la familia o con sus amigos.

En el primer caso, los padres de familia integran a sus hijos desde una edad muy temprana a la dinámica bilingüe de la comunidad. Esta consiste en usar cada una de sus dos lenguas de manera regular con redes sociales o personas distintas. Los papás hablan a sus hijos, en casa, en lengua indígena pero si están en otro contexto cambian de lengua, no sólo para dirigirse a sus interlocutores adultos, sino también para dirigirse a sus hijos. En estos casos las dinámicas de socialización incluyen rutinas en la que los padres de niños preverbales enseñan a sus hijos a usar una determinada lengua para una persona o grupo en contextos específicos. No existe una regla simple para explicar la selección de idioma, son varios elementos los que se conjugan para optar por una lengua u otra. Esta práctica está reforzada permanentemente por todos los miembros de la familia en su práctica bilingüe cotidiana. En el hogar, la gente usa a diario sus dos lenguas en infinidad de ocasiones. Esta dinámica es experimentada por el niño en todo momento. Además de la propia vivencia en un contexto bilingüe, los padres trabajan con sus hijos rutinas en las que se enfatiza la asociación de una determinada lengua con una persona. Cuando los padres de niños que están empezando a hablar enseñan a sus hijos cómo dirigirse a otra persona, utilizan la lengua apropiada para la ocasión.

En otros casos, es sólo uno de los padres quien usa mayoritariamente náhuatl con sus hijos mientras que la otra usa preferentemente español. Existen numerosos casos en los que el padre de familia es quien domina, además del náhuatl, un mayor nivel de español y la madre es más dominante en lengua indígena. Es este caso el padre usa español con sus hijos para garantizar que ellos aprendan esta lengua desde pequeños y la mamá usa náhuatl, ya que es la lengua que más domina y además es la lengua común entre todos los adultos.

Existen hogares en los que ambos padres de familia hablan a sus hijos sólo en español pero permiten que los niños hablen con sus abuelitos y otros adultos en náhuatl. Si bien la preocupación de los padres es que sus hijos dominen el español, no les niegan la posibilidad de aprender la lengua indígena con otras personas, ni penalizan su uso. Esta situación ilustra la funcionalidad de la familia extensa ya que al tener interlocutores distintos, los niños aprenden a usar sus dos lenguas con hablantes situados. Estos hablantes no son sólo los familiares directos, sino también los compañeros de juego o los compañeros de escuela como se ilustra en el siguiente caso.

Una mujer de San Isidro se casó con un hombre de una comunidad monolingüe en español que conoció mientras trabajaba en la ciudad de Puebla. Durante sus primeros 5 años de matrimonio vivieron en una comunidad enteramente hispanoparlante. Posteriormente regresaron a SIB y los niños comenzaron a aprender náhuatl con sus compañeros de juego:

«Nīniños in nicān nochpoca, in tētah āmo de oncā, entonces, o sea ôhuallahqueh āmo tlen cmatiah, āmo tlen ocmatiah de mexicano pero oncān yōyahqueh, nihqui yahueh 
nicān escuela, yahueh, moneloah īhuān niños de nicāh pos yeca, āxā más o menos ye tlahtoah, medio al revesado pero, pero ye cmatih» (Mujer, 50 años).

«En el caso de los niños de mi hija, el papá no es de aquí, entonces, o sea, [cuando los niños] vinieron [al pueblo] no sabían nada, nada sabían de mexicano pero allí ya fueron, van a la esuela aquí, van, se relacionan con los niños de acá pues ya, ahora más o menos ya hablan [náhuatl], medio cuatropeado pero ya lo saben» (Mujer, 50 años).

La práctica de hablar a los niños en náhuatl o de permitirles que la usen con algunos miembros de la familia está apoyada por un cuerpo de ideologías lingüísticas a favor del bilingüismo. El discurso metalingüístico más escuchado en la comunidad va en el sentido de que resulta necesario hablar dos lenguas. Las razones para ello van desde salvaguardar la histórica presencia del náhuatl en la comunidad, hablar con todos los miembros de su familia, hasta usarla como un recurso de defensa ya que al que no habla esta lengua se le pueden hacer bromas verbales aprovechando tal condición.

\subsubsection{Socialización predominantemente en español}

El tercer tipo corresponde a una realidad más actual, aunque no más general. Este fenómeno se ha hecho más notorio y sistemático especialmente entre los matrimonios jóvenes y entre los matrimonios que ya no participan del modelo de familia extensa. Bajo este modelo, los niños son socializados mayoritariamente en español aunque como hemos señalado líneas arriba, a través de la interacción con sus compañeros llegan a desarrollar, a escondidas de sus padres, cierta competencia comunicativa en lengua indígena. La diferencia con el grupo descrito anteriormente es que en estos casos, la concepción que los papás tienen de que los niños usen la lengua indígena es distinta. El siguiente extracto muestra cómo una abuelita califica como «maldades o bromas» el uso del náhuatl que realiza su nieto:

«Mis nietecitos, orita pues ya todo hablan en español, ya no hablan en, en este, en mexicano. Este niño (señala a un niño de aproximadamente 7 años), ay, a veces así, nos hace maldad (bromas) y nos dice: Abuelita, ¿Tlen tconchīhua?, eso quiere decir, ¿qué hace?, ¿Tlen tconchīhua? Pero eso, muy rara la vez, muy rara la vez dice eso» (Mujer, 65 años).

En otros casos, la práctica de usar sólo español está acompañada de una ideología que establece una relación directa entre la lengua indígena y algunos grupos de población bien definidos. Esta ideología relaciona el uso de la lengua indígena con el ser adulto, anciano y campesino. En algunos casos, la ideología es compartida por la mayoría de los miembros de la familia al grado que los abuelitos también hacen un esfuerzo para hablar con sus nietos sólo en español.

Como he señalado anteriormente, la existencia de niños que se asumen como enteramente monolingües en español, y que profesen tal ideología, no es muy grande pero es un signo importante para comprender lo que pasó en las otras comunidades de la región donde el náhuatl dejó de utilizarse por las generaciones de niños y jóvenes. Este análisis nos muestra que el desplazamiento lingüístico ocurrió en esta región 
debido, entre otros factores, a motivaciones ideológicas y no por la falta de input o por efecto directo y automático del contacto entre el español y la lengua indígena.

\section{Conclusiones}

La socialización infantil juega un papel muy importante en el mantenimiento y desplazamiento lingüístico. El caso SIB nos permite ver que en dicho proceso el náhuatl se mueve en un continuum que va desde las familias que usan más lengua indígena para hablar con sus niños hasta aquellas donde prácticamente no se le usa y se privilegia hablar sólo español. En medio de estos extremos encontramos al grueso de la población que practica una socialización infantil bilingüe. Esta diversidad en el patrón de uso del náhuatl tiene implicaciones muy importantes ya que de alguna manera está perfilando el proceso de desplazamiento ocurrido en otras comunidades donde una lengua va ganando mayores espacios mientras que la otra los va perdiendo.

Si partimos del dato censal que señala que más del $70 \%$ de la población es bilingüe náhuatl español y del trabajo etnográfico que muestra que dentro de la comunidad el bilingüismo es una práctica cotidiana, entonces se requiere una explicación que rompa la idea de que los bilingües usan su español sólo con aquellos que no hablan la lengua indígena. Para intentar explicar el funcionamiento de este sistema bilingüe nuestra unidad de análisis será más que la familia, la persona a nivel individual. Todos los individuos tienen una identidad lingüística, esta identidad no es universal frente a todos los demás, sino específica frente a determinados grupos o individuos. La identidad lingüística se construye como un elemento de su identidad cultural. En los discursos públicos entre los miembros de la comunidad, los ancianos y las personas ligadas primordialmente al campo se les identifica más con el habla náhuatl, mientras que a los jóvenes más con el español. Esto significa que los ancianos tiene como lengua primaria el náhuatl y como segundo recurso el español, y muchos jóvenes tienen como lengua primaria el español y como segundo recurso el náhuatl. Así, un anciano que regularmente habla con los adultos en náhuatl, usa el español (su segunda lengua) para dirigirse a las personas que no son de la comunidad y para hablar con otras, jóvenes principalmente, que aunque son de la comunidad son identificadas como usuarios de español. Estos jóvenes son bilingües pero también son los que mayor dominio de español han alcanzado dado que han cursado desde el preescolar hasta la preparatoria en esta lengua y aunque el preescolar y la primaria son bilingües, el $90 \%$ de sus clases la reciben en español. Estos niños y jóvenes han construido redes sociales a partir de la escuela en las que usan mayoritariamente el español pero cuando llegan a sus casas pueden hablar en náhuatl con sus padres, con sus abuelos o con amigos con quienes históricamente usan esa lengua para comunicarse.

Este último tema, la historicidad de las redes sociales es otro aspecto fundamental. En la comunidad se han construido patrones de interacción que practican tanto los adultos como los niños, en los que se ha establecido una lengua más o menos constante para hablar con sus pares. Por ejemplo, las personas adultas pueden haber desarrollado el habitus de hablar con sus padres en náhuatl y con sus hijos en español, pero cuando se tiene una visita en casa este patrón se modifica y se usa español entre todos 
los miembros de la familia, sin embargo, cuando la visita se marcha, los miembros vuelven a reproducir el habitus: náhuatl entre los adultos y español hacia los niños.

Por lo tanto, más que la competencia en cada lengua, lo que organiza el uso del repertorio lingüístico es la historicidad de las relaciones y las identidades de los interlocutores. Evidentemente esta es una propuesta de explicación, pero la realidad es más dinámica y nuevas formas de interacción surgen cuando un elemento de la cultura local se modifica.

Por otro lado, debido al alto índice de nahuahablantes adultos en la comunidad, al constante uso de esta lengua en las interacciones diarias y, sobre todo, a la ausencia de un cuerpo ideológico que de manera generalizada cancele la posibilidad de aprender náhuatl fuera del hogar, los niños que en sus hogares son interpelados sólo en español pueden llegar a alcanzar cierta competencia comunicativa en lengua indígena. Esta situación se presenta a la vez como una oportunidad y como un serio problema. La oportunidad supone que gracias a la actitud de respeto hacia la lengua indígena y a la existencia de un input lingüístico suficiente, están dadas las condiciones para que toda persona pueda, en cualquier momento de su vida, «empezar» aprender la lengua indígena. Este hecho posibilita la continuidad etnolingüística. Por otro lado, el hecho de que la gran mayoría de la gente participe, en algún momento, en interacciones en lengua indígena, hace poco visible que muchos de ellos, incluyendo niños, manejan muy pocos géneros discursivos en esta lengua.

Esto supone que el desplazamiento lingüístico del náhuatl no ocurre a nivel de lengua como sistema, sino a nivel de géneros discursivos y que el bilingüismo existente en la comunidad enmascara este proceso. Las fortalezas estructurales de la comunidad permiten que SIB exprese hoy una alta retención etnolingüística, por lo menos al nivel del número de hablantes, sin embrago, se precisan nuevas investigaciones para conocer las dinámicas que seguirán estos niños, saber si ampliarán su repertorio de géneros discursivos y cómo articularán sus dos lenguas con su, cada vez más fuerte, inmersión en la cultura hispanoparlante. Por otro lado, queda pendiente estudiar el papel de los nuevos agentes culturales como los profesores, los investigadores y las autoridades políticas. Si hoy algunas personas usan el español en su comunidad para hace saber que lo hablan, ¿qué sucederá cuando ya no haya dudas de que todos hablan español además de su lengua indígena? Estos y otros temas relacionados convierten a SIB en el escenario ideal para entender los nuevos procesos de retención y desplazamiento de las lenguas indígenas en México.

\section{Referencias bibliográficas}

Aztatzi, Pedro

1991 La danza de los vaqueros vasarios. México: Escuela de Antropología, Universidad Autónoma de Puebla. Manuscrito.

BAKHTin, Mikhail M.

1981 The Dialogic Imagination. Four Essays. Austin: University of Texas Press.

1986 «The problem of speech genres», en Speech genres and other late essays, Caryl Emerson y Michael Holquist, eds., pp. 60-102. Austin: University of Texas Press. 
BourdiEu, Pierre

1979 La distinction. París: Les Éditions de Minuit.

1980 Questions de sociologie. París: Les Éditions de Minuit.

1990 Sociología y cultura. México: Grijalbo-CONACULTA.

Crago, Martha

1992 «Ethnography and language socialization: a cross-cultural perspective». Topics in Language Disorders 12 (3): 28-39.

DE LEÓN, Lourdes

2005 La llegada del alma. Lenguaje, infancia y socialización entre los mayas de Zinacantán. México: CIESAS, CONACULTA, INAH.

FRANCIS, Norbert

1997 Malintzin. Bilingüismo y alfabetización en la sierra de Tlaxcala (México). Quito: Ediciones Abya-Yala.

GALINIER, Jacques

1990 La mitad del mundo. Cuerpo y cosmos en los rituales otomies. México: UNAM, Centro de Estudios Centroamericanos, INI.

Good, Catherine

2001 «La vida ceremonial en la construcción de la cultura: Procesos de identidad entre los nahuas de Guerrero», en Historia y vida ceremonial en las comunidades mesoamericanas: los ritos agrícolas, Johanna Broda y Catherine Good, coords., pp. 127-151. México: CONACULTA-INAH, UNAM.

\section{GosSEN Gary}

1977 «Chamula genres of verbal behavior». The Journal of American Folklore 84(331): 145-167.

1979 Los Chamulas en el mundo del sol: tiempo y espacio en una tradición oral Maya. México: Instituto Nacional Indigenista.

HiLl Jane H. y Kenneth C. HiLl

1986 Speaking Mexicano. Dynamics of Syncretic Language in Central Mexico. Tucson: The University of Arizona Press.

HyMes, Dell

1974 Foundations in Sociolinguistics. An Ethnographic Approach. Filadelfia: University of Pennsylvania Press.

LóPez Austin, Alfredo

1989 Cuerpo humano e ideología. Las concepciones de los antiguos nahuas. Serie Antropológica 39. México: IIA-UNAM.

MiLroy, Lesley

1980 Language and social networks. Oxford: Blackwell.

Milroy, Lesley y James MiLroy

1992 «Social network and social class: Towards an integrated sociolinguistic model». Language in Society 21 (1): 1-26.

Nutini, Hugo G. y Barry L. IsAAC

1974 Los pueblos de habla náhuatl de la región de Tlaxcala y Puebla. México: Instituto Nacional Indigenista y Secretaría de Educación Pública. 
OcHs, Elinor

1988 Culture and language development. Language acquisition and language socialization in a Samoan village. Cambridge: Cambridge University Press.

PARODI, Giovanni

2009 «Géneros discursivos y lengua escrita: Propuesta de una concepción integral desde una perspectiva sociocognitiva». Letras 51 (80): 19-55.

RENDÓN GARCINI, Ricardo.

1993 El Prosperato. Tlaxcala de 1885-1911. México: Universidad Iberoamericana, Siglo XXI.

RoBICHAUX, David

2007 «Identidades cambiantes: Indios y mestizos en el suroeste de Tlaxcala», en Cultura, poder y reproducción étnica en Tlaxcala, México. Osvaldo Romero, Guillermo Davinson, Magdalena Sam y Raúl Jiménez Guillen, comps., pp. 17-64. Tlaxcala: Universidad Autónoma de Tlaxcala.

SAUCEDO, Eduardo

2003 «Reciprocidad y vida social en la tarahumara: El complejo tesgüino y los grupos del sur de la Sierra», en La Comunidad sin límites. Estructura social y organización comunitaria en las regiones indígenas de México, vol. 3, Saúl Millán y Julieta Valle, coords., pp. 217-267. México: INAH, Colección Etnografía de los Pueblos Indígenas de México.

SCHIEFFELIN, Bambi B.

1990 The give and take of everyday life. Language socialization of Kaluli children. Cambridge: Cambridge University Press.

SCHIEFFELIN, Bambi B. y Elinor Ochs

1986 Language socialization across cultures. Cambridge: Cambridge University Press.

SiLVERSTEIN, Michael

1979 «Language structures and linguistic ideology», en The elements: A parasession on linguistic units and levels, Paul Clyne, William Hanks y Carol Hofbauer, eds., pp. 193-247. Chicago: Chicago Linguistic Society.

Terceros Ferrufino, Carmen R.

2002 Concepciones de infancia y práctica comunicativa de socialización en la niñez Quechua de Cororo-Bolivia. Tesis de Maestría en Lingüística Indoamericana. CIESAS.

VAN DiJK, Teun A.

1988 Ideología. Una aproximación disciplinaria. Barcelona: Gedisa

Woolard, Kathryn A.

1998 «Introduction, Language ideology as a field of inquiry», en Language ideologies: Practice and theory, Bambi B. Schieffelin, Kathryn A. Woolard y Paul Kroskrity eds., pp. 3-47. Oxford: Oxford University Press. 